\title{
Can public-private partnership (PPP) improve hospitals' performance indicators?
}

\author{
Peivand Bastani ${ }^{1}$, Omid Barati ${ }^{1,2}$, Ahmad Sadeghi*3 ${ }^{3}$, Sajad Ramandi ${ }^{4}$, Javad Javan-Noughabi ${ }^{5}$ \\ Received: 31 July 2017 \\ Published: 11 Feb 2019
}

\begin{abstract}
Background: This study was conducted to compare the main performance indicators of Hasheminejad hospital before and after implementing PPP model.

Methods: This cross sectional study was conducted in Iran in 2015. Performance indicators of Hasheminejad hospital, the only Iranian unit that implemented PPP model, were applied. Data were collected based on a researcher-designed checklist after ensuring its validity and reliability. Data were analyzed applying SPSS21, and the Shapiro-Wilk test was used to examine the relevant data normalization. After confirming the normality of the data, descriptive statistics and paired t test were used to analyze the data at a significant level of 0.05 .

Results: Dramatic variations were observed in the status of the studied indicators after the implementation of PPP in Hasheminejad hospital, and the changes were statistically significant in all these indicators $(\mathrm{p}<0.05)$

Conclusion: It seems that implementing PPP in Hasheminejad hospital can be considered as a successful experience in Iran's health sector. The significant improvement in this hospital's performance indicators can emphasize the effective role of PPP in administration of this hospital. However, service quality and patient satisfaction should be considered as qualitative indicators, along with the present quantitative indicators because better judgment about the changes was achieved in this hospital after implementing PPP.
\end{abstract}

Keywords: Public-private partnership, Performance analysis, Performance indicators, Hospital, Iran

Conflicts of Interest: None declared

Funding: Shiraz University of Medical Sciences

*This work has been published under CC BY-NC-SA 1.0 license.

Copyright $\subseteq$ Iran University of Medical Sciences

Cite this article as: Bastani $\mathrm{P}$, Barati O, Sadeghi A, Ramandi S, Javan-Noughabi J. Can public-private partnership (PPP) improve hospitals' performance indicators? Med J Islam Repub Iran. 2019 (11 Feb);33:4. https://doi.org/10.47176/mjiri.33.4

\section{Introduction}

Hospitals are considered as the most significant section of the health care systems worldwide, and, at the same time, they are the largest consumer of the rare sources allocated to the health sector (1). In developing countries, hospitals are accountable for almost $50 \%$ to $80 \%$ of the all health care system costs (2).

In Iran, as a sample of a developing middle-Eastern

\section{Corresponding author: Dr Ahmad Sadeghi, sadeghi.a@esfrums.ac.ir}

\footnotetext{
1. Health Human Resources Research Center, School of Management \& Information Sciences, Shiraz University of Medical Sciences, Shiraz, Iran

2. School of Health and Safety, Shahid Beheshti University of Medical Sciences, Tehran, Iran

3. Imam Khomeini Educational, Research and Treatment Center, Esfarayen Faculty of Medical Sciences, Esfarayen, Iran

4. Department of Health Management and Economics, School of Public Health, Tehran University of Medical Sciences, Tehran, Iran

5. Health Management and Economics Research Center, Iran University of Medical Sciences, Tehran, Iran
}

country, more than half of the health sector funds are allocated to hospitals (3). In this situation, low hospital bed occupancy rate, when compared with that of developed countries reflects the fact that the available resources are not distributed properly, which necessitates the use of right management methods (4). Therefore, policy-makers and senior officials are seeking ways to implement appro-

$\uparrow$ What is "already known" in this topic:

Public-private partnership (PPP) can be considered as a powerful political tool for improving and strengthening the survival of state-run hospitals and their quality of services. The implementation of PPP in many countries has shown its positive effects on health sector.

\section{$\rightarrow$ What this article adds:}

The collaborative model of Hasheminejad hospital and Moheb non-profit institution, which was implemented for the first time in the form of a PPP model in Iran, may have positive effects on hospital indicators. By localizing this model and adapting it to Iran's circumstances, a good development in the field of health sector can be achieved. 
priate policies and measures to improve the conditions of hospitals in the country, especially in the public sector. Taking advantage of the capacity and potential of the private sector in the hospital system noted in upstream documents, such as Article 44 of the Constitution of the Islamic Republic of Iran (5) and the Fourth and Fifth National Development Plans (6), is among these policies.

Public-private partnership (PPP) model was introduced in 1990 to use the capabilities of public and private sectors in the form of a hybrid model. PPP has been used constructively in recent years to reform health care sectors in many countries. In fact, PPP can be a powerful political tool for improving and promoting the survival and quality of services in public hospitals. Furthermore, PPP is trying to implement some of the principles of the private sector through a rigorous financial management, including economic balance and revenues, to solve some major problems in the public sector (7).

In Iran, for the first time, collaboration of governmental and non-governmental sectors in the health sector started with the cooperation of a non-profit patient support institution (Moheb) and Hasheminejad hospital to align the strengths of the public and private sectors and eliminate their weaknesses (8).

Hasheminejad is an educational specialist hospital in the field of urology and is affiliated to Iran University of Medical Sciences. During 2000 and 2003, this center was faced with serious challenges, such as financial constraints, lack of health facilities, and low-quality health care services. Partnership with a private partner seemed to be a good solution for these challenges, as the processes of modernization and equipment of the center in a traditional framework was time-consuming and lacked efficiency and required utility. Moheb institution was founded in 2004 based on legal opportunities with a mission to provide first-class services to low-income people using governmental tariffs. This institution started its partnership with Hasheminejad hospital according to PPP approach and by relying on provisions 87 and 88 of the Fourth Development Plan. The institution started its establishment and funding via leasing 2 parts of Hasheminejad hospital. The 2 sectors of Moheb (16 beds) and Mehr (16 beds) were the preliminary results of the partnership between Hasheminejad as a public hospital and Moheb institution as a private hospital. Following the increasing demand, the second phase of the partnership started with the long-term lease of the parking space of Hasheminejad hospital and the construction of Moheb e Mehr hospital in its vicinity. This hospital was built in 18 months with investment of Moheb institution and use of banking facilities and became operative in November 2009. Moheb e Mehr hospital is a public-private hospital which has been designed, built, financed, and operated (DBFO) by Moheb institution in agreement with the Co-Location Model in the vicinity of Hasheminejad hospital. The contract duration is 12 years since the start of the construction and 9 years since its operation. This hospital does not have any shareholders and does not receive any funding or assistance from governmental institutes or other organizations. In addition to launching a new hospital, this model provided a framework for modernization and equipment of the old state-run hospitals located in its vicinity. Profits from Moheb hospital activities are expended to equip and modernize Hasheminejad hospital and to expand and promote the services of Moheb hospital to other medical centers ( 9 , $10)$.

Considering Iranian experience in PPP and different benefits of implementing PPP in a hospital (eg, reducing governmental affairs and empowering the government to plan, set standards, finance, and make legislations; shifting the responsibility from the government to finance investments; using the element of competition to increase efficiency of the system, enhance self-management, and decentralize decision-making process, all of which emphasized in different studies (11)), this study was conducted to compare the main performance indicators of Hasheminejad hospital before and after implementing PPP model.

\section{Methods}

This was a cross sectional study conducted in 2015 in Hasheminejad hospital. Performance indicators of the hospital were analyzed to determine if changes in the performance indicators of Hasheminejad hospital have been made as a result of the adoption of the PPP model and the placement of a non-governmental hospital (Moheb) in the vicinity of a state-run medical center (Hasheminejad). To this end, the status of this hospital was studied for performance indicators in 2 time periods before and after the adoption of this model ( 3 years before and 3 years after the implementation of the model) (2007-2012). Bed occupancy rate (BOR), average length of stay (ALS), and bed turnover ratio were selected as the most significant indicators to assess hospital performance $(1,12)$. Moreover, other indicators, including number of surgeries, days of hospitalization, admission rate, the net number of deaths, and number of patients referring to the outpatient unit or clinic and emergency ward were included to be studied monthly.

Bed occupancy rate is defined as occupied bed day in a hospital in a determined period of time divided by total bed day multiple by 100 . According to Ministry of Health and Medical Education, the optimum range for BOR is more that $70 \%$. Average length of stay is another indicator. This indicator is occupied bed day in a determined hospital divided by all the alive and dead patients in a special period with the standard rate of less than 3.5 days. Bed turnover ratio is defined as ready bed day in a hospital in a specified time subtracted by the total of dead and discharged patients in the same time with the standard ratio of less than 2 days (13).

A researcher-made checklist was designed to compare the stated indicators. The efficacy indicators were studied 36 months before and after the implementation of PPP in the hospital. The quality and effectiveness indicators were omitted from the checklist because of the sensitivity and confidentiality of the data and the hospital's concerns. The checklist was designed in a way that all the indicators were separated according to month. The check list's face and content validity was confirmed by 4 health care and hospital management experts, and the checklist reliability 
was confirmed by Cronbach $\alpha>0.7$. Data obtained from this checklist were entered into SPSS statistical software [Version 16.0. Chicago, SPSS Inc] and STATA, and the Shapiro-Wilk test was used to examine the relevant data normalization. After confirming the normality of the data, descriptive statistics, paired t test, and Mann- Whitney were used for data analysis and trend analysis; significance level was set at 0.05 . At the same time, interrupted time series analysis, known as quasi-experimental time series analysis, was applied as an approach for the analysis of a single time series of data (here, the performance indicators of the studied hospital) known or estimated to be affected by interventions (controlled external influences) (14).

\section{Results}

The process of changes in the performance indicators of Hasheminejad hospital before and after the implementation of PPP (launching Moheb Mehr) has been studied (Table 1). As shown in Table 1, there are dramatic variations in the status of the studied indicators after the implementation of PPP in Hasheminejad hospital, and the changes were statistically significant in all these indicators $(\mathrm{p}<0.05)$.

Other results achieved from interrupted time series with 1-month interruption are presented in Table 2. Most of the hospital performance indicators had significant differences before and after the intervention.

Other findings indicated that the main performance indicators (ALS, BTO, BOR) increased during the first 6 months of 2007 to the first 6 months of 2012. These indicators included bed occupancy rate, average length of stay, and bed turnover, respectively (Fig. 1). These findings are considerable because Hasheminejad hospital's human resources have been consistent during the previous study years.

Figure 2 compares the trend fluctuations of all the 8 studied indicators in a snapshot. As Figure 1 demonstrates, 2 indicators, number of deaths and average length of stay, had a decreasing trend and most of other indicators had increasing trends, indicating improvement in the hospital's performance after implementation of PPP.

\section{Discussion}

Based on Co-Location Model, Moheb Mehr hospital, a public-private hospital, was built in the vicinity of Hasheminejad hospital (a public hospital).

According to the results of this study, improvements in hospital performance indicators and quality of services are among the most important achievements and implications of implementing PPP in the provision of hospital services in Iran. Thus, after the implementation of PPP, positive effects will be observed on hospital performance indicators. The results of an investigation by Shadpour et al (15) showed that through the implementation of PPP model, a significant growth in the provision of hospital services in Hasheminejad hospital was observed. In fact, following a partnership with a non-governmental hospital (Moheb), there was no longer a need to refer patients to other centers, and waiting time for services also reduced, which increased the number of clients and reduced out-of-pocket expenses. Similar results have been obtained in other studies. The results of a study in Sao Paulo in Brazil revealed that PPP-based hospitals have a better performance and efficiency in terms of bed circulation, bed occupancy, length of stay, and mortality rate when compared with other hospitals in the area (16). The results of another study in Alzira in Spain suggested that costs were decreased by $25 \%$ in PPP-based hospitals compared to those in public hospitals. In addition, patients' length of stay and the waiting time to get services have been lowered in PPPbased hospitals (17). In Lesotho, the state-managed hospital network was compared with PPP-managed hospital network for capacity, utilization, clinical quality, and pa-

Table 1. The status of performance indicators in Hasheminejad hospital before and after the implementation of PPP model

\begin{tabular}{|c|c|c|c|c|c|c|c|}
\hline \multirow[t]{2}{*}{ Performance indicators } & \multicolumn{2}{|c|}{ Mean and standard deviation } & \multirow[t]{2}{*}{ Variation rate } & \multirow[t]{2}{*}{ Mann-Whitney U } & \multirow[t]{2}{*}{ Wilcoxon W } & \multirow[t]{2}{*}{ Z } & \multirow[t]{2}{*}{$\mathrm{p}$} \\
\hline & Before PPP & After PPP & & & & & \\
\hline Bed occupancy rate & $76.18 \pm 7.08$ & $81.36 \pm 4.61$ & +5.18 & 649 & 1145 & -2.72 & 0.006 \\
\hline Average length of stay & $5.10 \pm 0.24$ & $4.46 \pm 0.32$ & -0.64 & 61 & 2141 & -7.39 & $<0.001$ \\
\hline Bed efficiency or circulating & $4.62 \pm 0.54$ & $5.72 \pm 0.52$ & +1.10 & 110 & 606 & -7.00 & $<0.001$ \\
\hline Days of hospitalization & $2861 \pm 469$ & $3167 \pm 412$ & +306 & 515 & 1011 & -3.79 & $<0.001$ \\
\hline Number of admissions & $565 \pm 80$ & $708 \pm 72$ & +143 & 141.5 & 637.5 & -6.75 & $<0.001$ \\
\hline Clinic referrals & $4168 \pm 1048$ & $5250 \pm 581$ & +1082 & 214 & 710 & -6.18 & $<0.001$ \\
\hline Emergency referrals & $1686 \pm 449$ & $2239 \pm 441$ & +553 & 202 & 698 & -6.27 & $<0.001$ \\
\hline Number of surgical operations & $650 \pm 151$ & $1061 \pm 130$ & +411 & 55 & 551 & -7.44 & $<0.001$ \\
\hline Number of deaths & $1.65 \pm 0.79$ & $1.55 \pm 0.79$ & -0.10 & 478.5 & 2558.5 & -4.08 & $<0.001$ \\
\hline
\end{tabular}

Table 2. Results of trend analysis according to the intervention with 1-month interruption

\begin{tabular}{|c|c|c|c|c|c|c|c|c|}
\hline \multirow[b]{2}{*}{ Variables } & \multicolumn{2}{|c|}{ Intercept } & \multicolumn{2}{|c|}{ Pre-intervention slope } & \multicolumn{2}{|c|}{ Change in slope } & \multicolumn{2}{|c|}{ Change in the intercept } \\
\hline & Value & $\mathrm{SE}$ & Value & $\mathrm{SE}$ & Value & $\mathrm{SE}$ & Value & $\mathrm{SE}$ \\
\hline Number of surgical operations & 11.67 & -2.013 & $125 / 8$ & $-46 / 53$ & $-8 / 233$ & -2.173 & 454.3 & -37.18 \\
\hline Bed occupancy rate & 0.142 & -0.146 & 2.968 & -2.724 & -0.175 & -0.152 & 73.54 & -2.689 \\
\hline Average length of stay & 0.00302 & -0.00524 & -0.529 & -0.122 & -0.0120 & -0.00574 & 5.061 & -0.123 \\
\hline Bed efficiency or circulating & 0.0176 & -0.0105 & 0.649 & -0.201 & -0.0103 & -0.0109 & 4.313 & -0.21 \\
\hline Days of hospitalization & $22 / 64$ & $-9 / 161$ & $-33 / 96$ & $-168 / 2$ & $-23 / 79$ & $-9 / 562$ & 2,478 & $-182 / 2$ \\
\hline Number of admissions & 3.785 & -1.533 & 63.08 & -29.8 & -2.772 & -1.61 & 499.9 & -31.24 \\
\hline Number of deaths & -0.0353 & -0.0195 & 0.313 & -0.298 & 0.0212 & -0.0198 & 2.697 & -0.416 \\
\hline Clinic referrals & 90.89 & -10.46 & -637.8 & -270.2 & -65.25 & -11.32 & 2,660 & -167.9 \\
\hline Emergency referrals & 45.3 & -3.046 & -828.4 & -124.3 & -3.025 & -4.384 & 949.7 & -65.11 \\
\hline
\end{tabular}


Public-private partnership and performance indicators

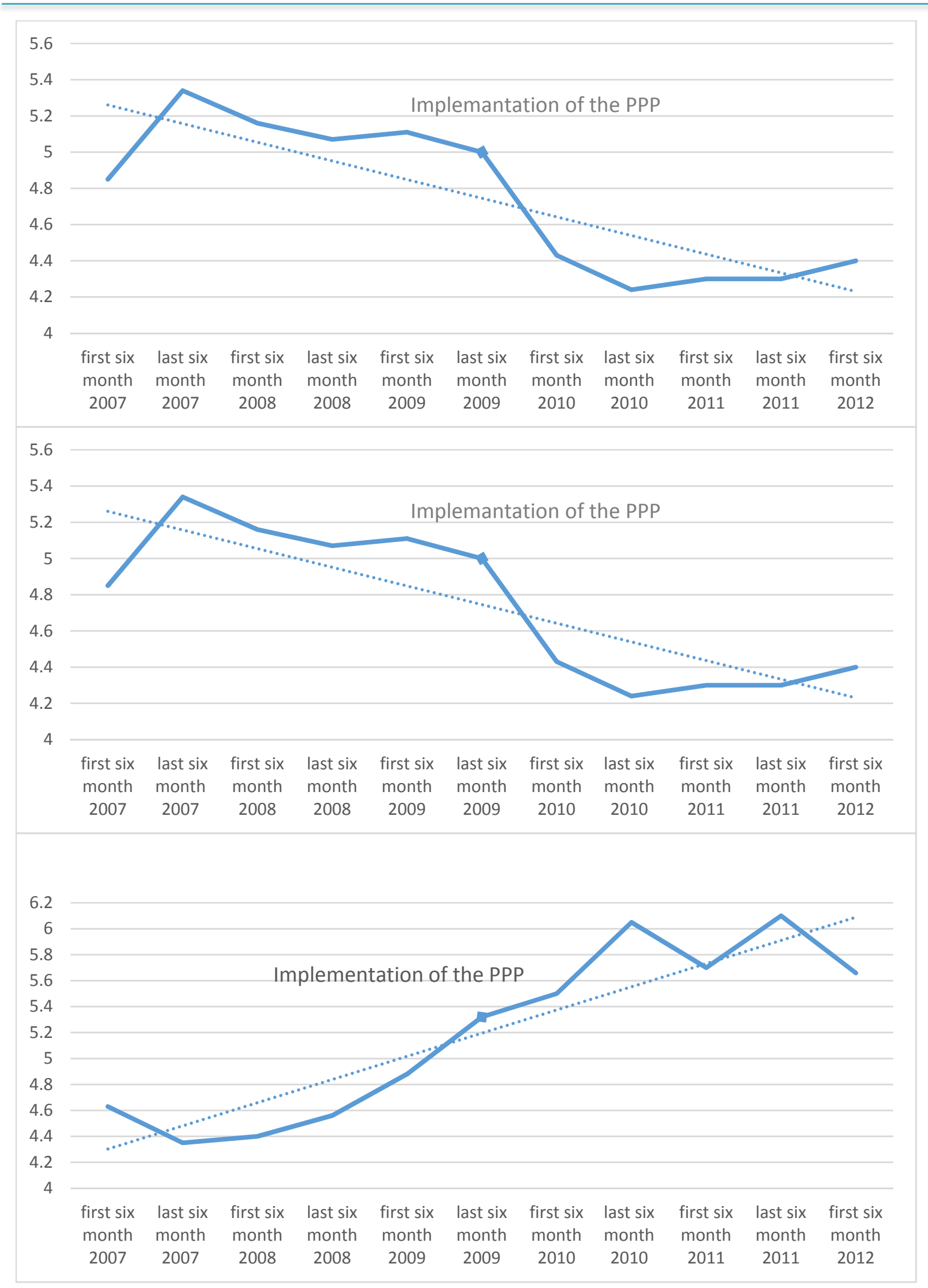

Fig. 1. Trend analysis of bed occupancy rate, average length of stay, and bed turnover

tient outcome, and the results showed the provision of high-quality services and obtaining remarkable achievements in the clinical outcomes of PPP-based hospitals (18).

\section{$4 \quad$ http://mjiri.iums.ac.ir}

Med J Islam Repub Iran. 2019 (11 Feb); 33:4.
In the present study, these significant changes in Hasheminejad hospital after implementing PPP are comparable with the whole performance ratios of Iranian governmental hospitals. Bastani et al found a high degree of 

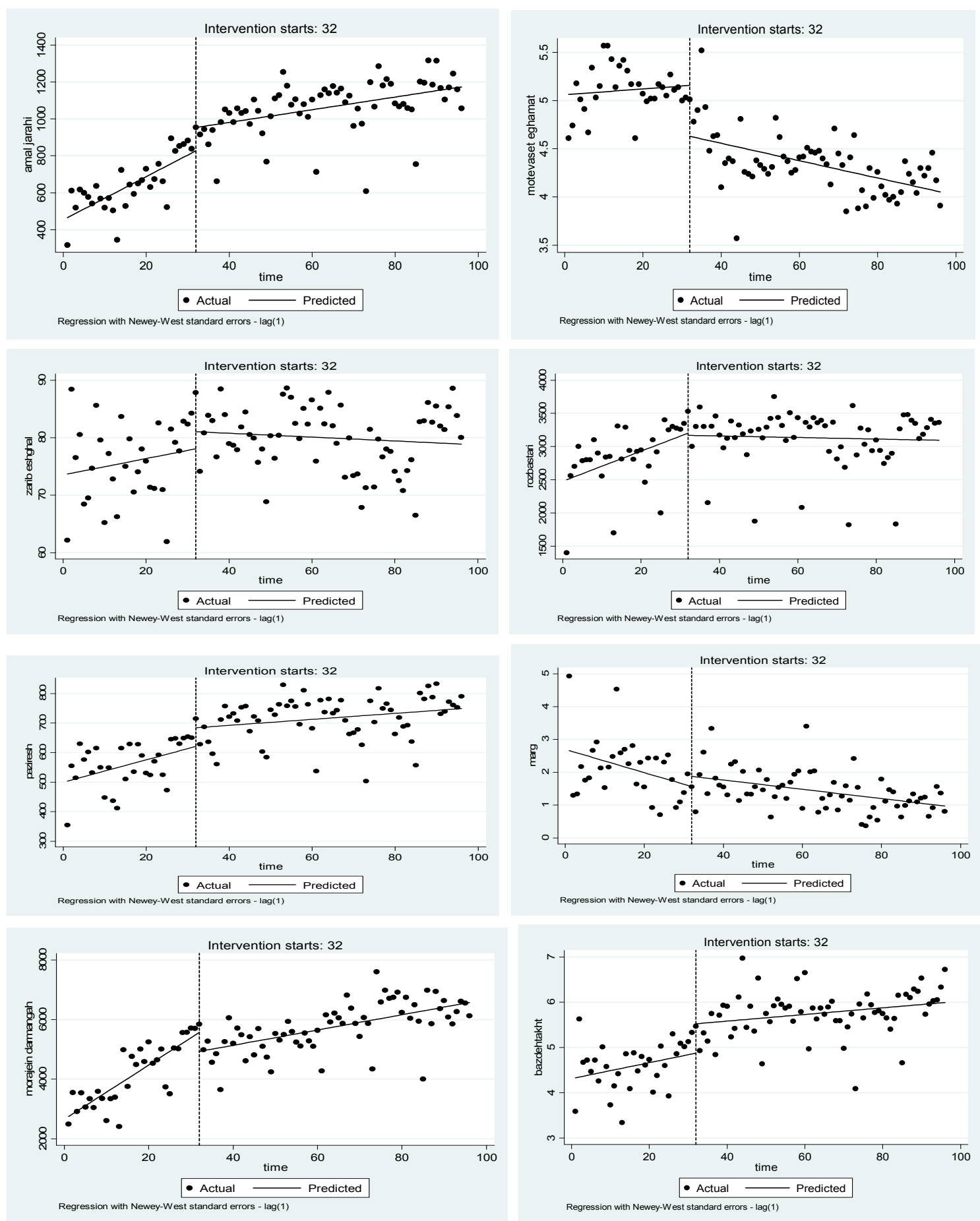

Fig. 2. Trends of the 8 studied indicators

fluctuation in Iranian governmental hospitals' bed occupancy rate from $31.4 \%$ as the minimum level in under 50 bed hospitals to $63.4 \%$ in more than 300 bed hospitals (1). Their results indicated a significant difference between the BOR of governmental hospitals and that of Hasheminejad hospital, with the average of $81 \%$, after implementation of PPP.

Furthermore, although comparing the 4.46 days as ALS for this hospital after PPP indicates a moderate status according to Iranian Ministry of Health and Medical Education's standards, it shows an improvement in this indicator when compared to its poor status before PPP, according to the above standards (19).

One of the limitations of this study was ignoring the quality of services along with quantitative ratios. In this regard, perceived quality of hospital care, as evidenced by the satisfaction and perception ratings of responders, the time spent waiting for treatment, and manner of support staff were better in a PPP-model hospital in India (20). Thus, it is recommended that future studies analyze the impacts of PPP in Hasheminejad hospital on the qualitative aspects, including accessibility of health facility, time 
spent waiting, manner and quality of physician, nurses, supporting staff, and other personnel, perception of equipment, explanation of treatment details and general comfort.

\section{Conclusion}

It seems that implementing PPP in Hasheminejad hospital can be considered as a successful experience in Iran's health sector. The significant improvement in this hospital's performance indicators emphasizes the effective role of PPP in administration of this hospital. However, service quality and patient satisfaction should also be considered as qualitative indicators along with the present quantitative ones to have a better understanding of the changes that have occurred in this hospital after PPP.

\section{Acknowledgments}

This article was part of a Ph.D. thesis in the field of health care management, and it was approved and supported financially by Shiraz University of Medical Sciences, Shiraz, Iran (grant No. 94-7502). The authors express their gratitude to Shiraz University of Medical Sciences and Hasheminejad hospital for their kind cooperation.

\section{Conflict of Interests}

The authors declare that they have no competing interests.

\section{References}

1. Bastani P, Vatankhah S, Salehi M. Performance Ratio Analysis: A National Study on Iranian Hospitals Affiliated to Ministry of Health and Medical Education. Iran J Pub Health. 2013;42(8):876-882.

2. Barati Marnani A, Sadeghifar J, Pourmohammadi K, Mostafaie D, Abolhalaj M, Bastani P. Performance assessment indicators: How DEA and Pabon Lasso describe Iranian hospitals' performance. Health Med. 2012;6(3):791-6.

3. Abolhallaje M, Ramezanian M, Abolhasani N, Salarian Zade H, Hamidi $\mathrm{H}$, Bastani P. Iranian health financing system: challenges and opportunities. World Appl Sci J. 2013;22(5):662-6.

4. Lotfi F, Kalhor R, Bastani P, Shaarbafchi Zadeh N, Eslamian M, Dehghani MR, et al. Various indicators for the assessment of hospitals' performance status: differences and similarities. Iran Red Cresc Med J. 2014;16(4):e12950.

5. The general policies of the Article 44 of the Constitution of the Islamic Republic of Iran. Available at: http://www.en.ipo.ir/index.aspx? siteid=83\&pageid $=822$.

6. Nikjoo RG, Beyrami HJ, Jannati A, Jaafarabadi MA. Prioritizing Public-Private Partnership Models for Public Hospitals of Iran Based on Performance Indicators. Health Promot Perspect. 2012;2(2):251.

7. Sadeghi A, Barati O, Bastani P, Daneshjafari D, Etemadian M. Experiences of selected countries in the use of public-private partnership in hospital services provision. J Pak Med Assoc. 2016;66:1401-6.

8. Sadeghi A, Barati O, Bastani P, Daneshjafari D, Etemadian M. Strategies to develop and promote public-private partnerships (PPPs) in the provision of hospital services in Iran: a qualitative study. Electro Physician. 2016;8(4):2208-14.

9. Etemadian M, Shadpour P, Soleimani MJ, Biglar M, Hadi Radfar M, Jarrahi M. Iranian-Islamic Model of Public-Private Partnership in Hospital Management: Introducing Moheb Hospital Model. Int J Hosp Res. 2013;2(2):95-108.

10. Moheb: Different Pathway. Iran: Tehran: Moheb Institution; 2013.

11. Alfen HW, Kalidindi SN, Ogunlana S, Wang S, Abednego MP, Frank-Jungbecker A, et al. Public-Private Partnership in infrastructure development: Case studies from Asia and Europe. 2009;7.

12. Hasani SA, Abolhalaj M, Behmaneshnia M, BastaniP,
RamezanianM, Najafi B, et al. Specific Revenue of Iranian Medica Science Universities within 2001-2010. World Appl Sci J. 2013;22(4): 479-84.

13. Ghorbani nia R, Ahmadian Kh, Ranjbar Z. To Compare the Performance Indexes of Selected Hospital with National Standards. J Health Promot Manag. 2017;7(3):1-6.

14. Michielutte R, Shelton B, Paskett ED, Tatum CM, Velez R. Use of an interrupted time-series design to evaluate a cancer screening program. Health Educ Res. 2000 Oct 1;15(5):615-23.

15. Shadpour P, Barzegar M, Afzal E. Study on the Impact of Implementing Public-Private Partnership (PPP) at Hasheminejad Kidney Center. Int J Hosp Res. 2013;2(4):195-200.

16. La Forgia GM, Harding A. Public-private partnerships and public hospital performance in São Paulo, Brazil. Health Aff. 2009;28(4):1114-26.

17. Sekhri N, Feachem R, Ni A. Public-private integrated partnerships demonstrate the potential to improve health care access, quality, and efficiency. Health Aff (Millwood). 2011;30(8):1498-507.

18. McIntosh N, Grabowski A, Jack B, Nkabane-Nkholongo EL, Vian T. A Public-Private Partnership Improves Clinical Performance In A Hospital Network In Lesotho. Health Aff (Millwood). 2015;34(6):954-62.

19. Jonaidi N, Sadeghi M, Izadi M, Ranjbar R. Comparison of performance indicators in one of hospitals of Tehran with national standards. Iran J Mil Med. 2011;12(4):223-8.

20. Baliga BS, Ravikiran SR, Rao SS, Coutinho A, Jain A. PublicPrivate Partnership in Health Care: A Comparative Cross-sectional Study of Perceived Quality of Care Among Parents of Children Admitted in Two Government District-hospitals, Southern India. J Clin Diagn Res. 2016;10(2):5-9. 